\title{
IDENTIDAD, COSMOPOLITISMO Y EDUCACIÓN EN LAS BANDAS DE METAL EXTREMO: EL CASO DE FINLANDIA
}

\author{
Identity, Cosmopolitanism and Education in extreme metal \\ bands: the case of Finland
}

\section{Eugenio Otero Urtaza ${ }^{\alpha}$}

Fecha de recepción: 22/01/2020 • Fecha de aceptación: 08/03/2020

Resumen. La música es un arte que define muchas veces la educación y valores de las personas. El Metal Extremo es un género musical controvertido que a veces, en alguno de sus subgéneros, ha provocado episodios de excepcional violencia. Los metaleros conforman un movimiento cultural que está presente en todos los continentes. Las corrientes metaleras son difíciles de disolver en el magma de la aceptación social: crean una conciencia de solidaridad transnacional, de contestación al derroche y ostentación que destruye el planeta, al mismo tiempo que reivindican el lugar en que se vive. El Metal Extremo no es una moda artística, está cambiando profundamente la mentalidad de muchos jóvenes que rechazan la organización social del mundo capitalista y cristiano y tratan de encontrar alternativas de futuro. En este artículo nos preguntamos cómo se forman sus convicciones y en qué sentido les influyen las enseñanzas de la escuela. Una de las maneras de estudiar el fenómeno es analizando las letras de las canciones. No se puede atender a todos los subgéneros y se ha optado por estudiar a tres grupos de Melodic Death Metal de Finlandia, especialmente en relación con el sentimiento que tienen sobre la naturaleza y el cosmos. Se evidencia que sus canciones parten, con frecuencia, de poemas clásicos y populares que se conocen por la escuela, por la herencia que han dejado los grandes poetas fineses, e incluso de las creaciones literarias de los músicos por esa resonancia escolar.

Palabras clave: Metal extremo y educación; Identidad personal y música: Educación informal; Historia del Heavy Metal.

\footnotetext{
a Departamento de Pedagogía y Didáctica. Facultad de Formación del Profesorado. Universidad de Santiago de Compostela (Campus de Lugo). Avenida de Ramón Ferreiro s/n, 27002 Lugo. España. otero.urtaza@usc.es (D) ORCID: https://orcid.org/0000-0002-1697-418X
}

Cómo citar este artículo: Otero Urtaza, Eugenio. «Identidad, Cosmopolitismo y Educación en las bandas de metal extremo: el caso de Finlandia». Historia y Memoria de la Educación 12 (2020): 271-302 
Abstract. Music is an art that often defines the education and values of people. Extreme Metal is a controversial musical genre that at times, in some of its subgenres, has caused episodes of exceptional violence. Metalheads make up a cultural movement that is present on all continents. Metal currents are difficult to dissolve in the magma of social acceptance: they create a consciousness of transnational solidarity, of response to waste and ostentation that destroys the planet, while claiming the place in which it is lived. Extreme Metal is not an artistic fashion, it is profoundly changing the mentality of many young people who reject the social organisation of the capitalist and Christian world and try to find alternatives for the future. In this article we ask how their convictions are formed and in what way the school's teachings influence them. One of the ways of studying the phenomenon is by analysing the lyrics of the songs. Not all subgenres can be covered and three Melodic Death Metal bands from Finland have been chosen for study, especially in relation to their feelings about nature and the cosmos. It is evident that their songs are often based on classical and popular poems learned at school? by the legacy left by the great Finnish poets, and even by the literary creations of musicians for that school resonance.

Keywords: Extreme metal and education; Personal identity and music; Informal education; History of Heavy Metal

Nothing here is built to last Neverlast (2019). Niilo Sevänen

\section{INTRODUCCIÓN}

Los movimientos musicales que han derivado del heavy metal, suelen ser poco conocidos más allá de sus círculos de seguidores fieles. Hacen una música con sonidos de guitarra distorsionados, con un fuerte protagonismo del bajo y la batería, voces guturales con bramidos y aullidos en tono muy alto o grave que resultan agresivos para quienes están instalados en músicas más frecuentadas y cómodas. Son estilos musicales que hacen desde voces finas, operísticas y melódicas hasta rugidos desgarrados que en inglés llevan la vehemente denominación de growl: 1 es el Metal Extremo. No obstante, el Metal Extremo es música popular que,

\footnotetext{
${ }^{1}$ El death growl es una técnica muy usual en este tipo de música. Es una voz que suena como un grito animal, que debe ser entrenada para que no dañe las cuerdas vocales. Sobre sus propiedades musicales véase, Keizo Kato y Akinori Ito, «Acoustic Features and Auditory Impressions of Death Growl and Screaming Voice», en Proceedings of the 2013 Ninth International Conference on Intelligent Information Hiding and Multimedia Signal Processing (Beijing, China,: IEEE, 2013), 460-463. https:// doi.org/10.1109/IIH-MSP.2013.120
} 
generalmente, se ha asentado con artistas aficionados que se mueven en unos contextos sociales en que han ganado un espacio de inclusión. Los metaleros suelen estar bien integrados en su entorno, aunque la organización social no les guste nada, o casi nada. Su modo de vida no suele ser escandaloso, y desde luego es menos desvergonzado que el de muchos rockeros clásicos. Pocos de ellos juegan a convertirse en arquetipos manipulables por el mercantilismo: no les suele interesar enriquecerse con la música y odian «estar de moda». Aunque su aspecto inquieta a las personas que mantienen estilos de vida convencionales, no siempre fuman o beben en exceso y los posmilénicos², la Generación Z, muy raramente consume drogas. Son personas tranquilas. Algunas practican el veganismo y no es infrecuente que militen en partidos animalistas. La inquietud por la preservación del medio ambiente suele estar entre sus prioridades.

La música sirve a muchos jóvenes para desarrollar una identidad social. Cuando algunos grupos de rock empezaron a dar más protagonismo al bajo y al baterista, se denominó a este estilo hard rock que desembocó en un género musical donde las guitarras empezaron a acelerar los tiempos y las voces a liberarse en timbres graves o aullidos, con letras más agresivas y obscuras. A ese estilo se le conoce como heavy metal ${ }^{3}$. Pero ese movimiento empezó hacia 1980 a transformarse en unas bandas que vistas desde el exterior presentan una diversidad de ideas y estilos que no son siempre identificables como rock, con una sorprendente recurrencia a temas de música clásica y de las corrientes folk, y a sonidos potentes, especialmente en la voces. El heavy metal se ha diversificado en muchos estilos concretos que en algunos casos son criticados porque la música académica, a la que a veces recurren, se diluye en formas complejas «con

\footnotetext{
2 Michael Dimock, «Defining generations: Where Millennials end and Generation Z begins», Pew Research Center (January 17, 2019). Disponible en https://www.pewresearch.org/fact-tank/2019/01/17/ where-millennials-end-and-generation-z-begins/ (Consultado el 12/12/2019). Dimock considera que el intervalo de la Generación Z, se sitúa en los nacidos entre 1996 y 2012.

${ }^{3}$ La expresión «heavy metal» aparece por primera vez en la novela de William Burroughs, The Soft Machine, publicada en 1961, mediante el personaje «Uranian Willy The Heavy Metal Kid». No obstante, la popularización del término llegó con la canción «Born to be Wild», del grupo Steppenwolf, escrita por Mars Bonfire que dice: I like smoke and lightning/Heavy metal thunder/Racin' with the wind/And the feelin' that I'm under. Como es bien conocido, esta canción abre la película Easy Rider (1968) de Dennis Hopper. Véase Deena Weinstein, «Just So Stories: How Heavy Metal Got Its Name-A Cautionary Tale», Rock Music Studies 1, no. 1 (2014): 37-38. https://doi.org/10.1080/19401 159.2013 .846655
} 
un sonido distintivo que luego es fragmentado por la audiencia y el artista» ${ }^{4}$. El metal extremo, podría definirse "como una tendencia musical popular basada en el rock, cuyos orígenes se remontan a los primeros años ochenta, que se caracteriza por englobar bajo dicho término-paraguas gran cantidad de formas y estilos musicales, muchos de ellos con pocos rasgos comunes, aunque todos basados en la búsqueda de los sonidos más extremos (obscuros, veloces, lentos, violentos) que la música pueda crear». ${ }^{5}$

El rechazo social a estos movimientos es todavía muy vivo, a pesar de que algunos de los grandes festivales musicales se nutren de decenas de miles de jóvenes que acuden a escuchar a estas bandas desde sus lugares de origen, lo que permite fortalecer sus comunidades y mostrar su poder. ${ }^{6}$ No obstante, sigue siendo una música muy poco aceptada en el mundo académico. El estereotipo que se tiene de un metalero suele asociarse a jóvenes con escasa educación, abuso de drogas y alcohol, conductas sexuales de riesgo, tendencias suicidas y creencias satánicas y ocultistas. $^{7}$ Les caracteriza una melena larga que agitan con ímpetu al ritmo de la música, brazos tatuados y el uso de camisetas en las que predomina el color negro, con motivos fúnebres. Suele pensarse que son autodestructivos y en Estados Unidos incluso se ha considerado que tienen una fuerte capacidad para dañar con sus ideales a los jóvenes que los siguen. ${ }^{8}$ Es un movimiento que se consolidó tras el auge del punk, pero al contrario que el punk, no pretender crear «un rechazo sociopolítico del mundo en un reducto squatter», sino abrazar de manera decidida

\footnotetext{
${ }^{4}$ Ross Wilson, «Folk Metal Case Study», en Inmortalis Productions. Disponible en https://rosswilsondrmetal.wordpress.com/ (Consultado el 16/10/2019)

${ }_{5}^{5}$ Salva Rubio, Metal Extremo. 30 años de obscuridad (1981-2011) (Lleida: Editorial Milenio, 2011), 25 .

6 Deena Weinstein, «The Concert: Metal Epiphany», en Heavy Metal. A Cultural Sociology (New York: Lexington Books An Imprint of MacMillan Inc., 1991), 222-225.

${ }_{7}^{7}$ Carrie B. Fried, «Stereotypes of Music Fans: Are Rap and Heavy Metal Fans a Danger to Themselves or Others?», Journal of Media Psychology 8, no. 3 (2003): 2. Disponible en: https://www.researchgate.net/publication/228772092 (Consultado el 14/10/2019)

8 Jeffrey Arnett, «Adolescents and Heavy Metal Music. From the Mouths of Metalheads», Youth \& Society 23, no. 1 (1991): 76-77. https://doi.org/10.1177/0044118X91023001004. En Estados Unidos hubo una fuerte preocupación en las asociaciones de padres por el contenido de las letras referidas al suicidio y el satanismo, con contenido destructivo o autodestructivo, y la frecuencia con que los jóvenes, hospitalizados en psiquiátricos, se referían al heavy metal como su música preferida.
} 
«el lado más oscuro, sardónico, irreverente y contrario al desgraciado mundo que se les venía encima». ${ }^{9}$

El tema que se plantea en este artículo no tiene antecedentes en los estudios que se realizan en la historia de la educación en España. ¿Cómo influye en la mentalidad de los jóvenes su adscripción a un movimiento musical? ¿Son los metaleros el producto de un rechazo a los valores escolares del capitalismo naturalizado como una realidad de sentido común? ${ }^{10}$ Estos movimientos tienen incidencia en el periodo final de la adolescencia, y es posible que en esos años marquen un conjunto de valores indelebles. En el caso del Metal Extremo es habitual el empleo de canciones con letras sobre el satanismo y seres fantásticos, el sacrificio, el sufrimiento, el fin de toda esperanza, la corrupción política, la destrucción de la naturaleza, la muerte, el terror, la sangre y la venganza, el regreso al paganismo, que parecen marcar un perfil de personas que viven al límite de un abismo. Las corrientes metaleras son difíciles de disolver en el magma de la aceptación social: crean una conciencia de solidaridad transnacional, de contestación al derroche y ostentación que destruye el planeta, al mismo tiempo que reivindican el lugar en que se vive. Provocan un «desorden cultural» que mezcla elementos propios y ancestrales con ideas cosmopolitas, compartidas por conductos subterráneos o redes sociales, procurando apartarse de la vigilancia de las superestructuras políticas. ${ }^{11}$

Los movimientos musicales de Metal Extremo no quieren dejarse controlar por los poderes instituidos. Es una identidad de resistencia que comporta un estilo de vida que se asume en la cotidianeidad y se manifiesta artísticamente. Cierto que todos los movimientos sociales son incorporados con el tiempo a las corrientes medulares de una organización

\footnotetext{
9 Rubio, Metal Extremo, 51.

10 Peter McLaren, «Revolutionary Pedagogy in Post-revolutionary Times: Rethinking the Political Economy of Critical Education», Educational Theory, 48, no. 4 (1998): 435.

11 Nos referimos con este concepto al análisis que realiza Jesús Martín-Barbero en «Jóvenes: des-orden cultural y palimpsestos de identidad», en Viviendo a toda. Jóvenes, territorios culturales y nuevas sensibilidades, ed. Humberto J, Cubides et al. (Santa Fe de Bogotá, Colombia: Siglo de Hombre Editores, 1998), 22-37. Para explicar que quiere decir con «desorden cultural» hace un símil con un palimpsesto, donde «un pasado borroso emerge, tenazmente aunque borroso, en las entrelíneas que escriben el presente». Un movimiento «des-historizador y des-territorializador» que atraviesa las demarcaciones culturales y así, des-localizadas, «las culturas tienden a hibridarse como nunca antes».
} 
social más compleja, aunque eso comporta cambios en el caudal central, que termina asumiendo las corrientes marginales. No obstante, el Metal Extremo es poco amable en su expresión musical, y eso le lleva a mantenerse en el margen. Subgéneros como el Black Metal, el Doom Metal, el Power Metal, el Death Metal están muy extendidos no solo en Estados Unidos o Alemania. Finlandia es una potencia metalera, y en España aunque rara vez llama la atención de los medios de comunicación, el movimiento está presente en todas las ciudades y es frecuente que las villas grandes también cuenten con una banda de alguno de estos subgéneros. Conforme la Encyclopaedia Metallum hay 3.848 grupos musicales de estos estilos actualmente en España. ${ }^{12}$

\section{LAS CANCIONES DEL METAL EXTREMO Y SUS METÁFORAS}

La educación informal ${ }^{13}$ no siempre es un campo sencillo para la investigación histórico-pedagógica. Es un proceso que no suele dejar documentación oficial, ni transcurre en espacios o lugares reservados para la actividad educativa. La educación fuera de las instituciones y la intencionalidad de control de los adultos es un elemento constitutivo de una gran fuerza en una persona. El peso de los iguales, es a veces mucho más poderoso que el de la escuela y la propia familia. Pero con frecuencia es invisible para las instituciones cuyo cierre hacia la cultura marginal de las generaciones emergentes produce conflictos sempiternos. La rebeldía juvenil es tema frecuente de los análisis sociológicos y desde la pedagogía social se estudia más como un ámbito de intervención reglada que como un acervo que rompe con un orden mental constituido. No obstante, estos movimientos tienen una fuerza extraordinaria que cambia el mundo, los hábitos de conducta individual, la idea de familia, las actitudes políticas, o las inclinaciones artísticas. Fenómenos que se produjeron en la segunda mitad del siglo pasado como el festival de Woodstock,

\footnotetext{
${ }^{12}$ Encyclopaedia Metallum. The Metal Archives, https://www.metal-archives.com/lists/ES (Consulta realizada el 9/03/2020)

13 Seguimos el significado de educación informal que establecieron Coombs y Ahmed: «proceso que dura toda la vida y en el que las personas adquieren y acumulan conocimientos, habilidades, actitudes y modos de discernimiento mediante las experiencias diarias y su relación con el medio ambiente; esto es, en la casa, en el trabajo, divirtiéndose; con el ejemplo y las actitudes de sus familias y amigos; mediante los viajes, la lectura de periódicos y libros, o bien escuchando la radio, la televisión y el cine». Véase Philip H. Coombs y Manzoor Ahmed, La lucha contra la pobreza rural. El aporte de la educación no formal (Madrid: Tecnos, 1975), 27.
} 
el mayo francés o la revuelta de Berkeley, dieron paso a la libertad sexual que en nuestro tiempo se ha transformado en una legislación que permite la existencia de modelos de familia y de relaciones afectivas entre las personas que eran impensables tras el fin de la Segunda Guerra Mundial.

Los cambios culturales que provocan las generaciones emergentes tienen expresiones artísticas que chocan con el orden mental de los valores constituidos. Uno de ellas, es la musical, que a partir de 1960, con la inclusión de instrumentos eléctricos, el baterista y la difusión del disco de vinilo, abrió el paso a una generación que provocó la irrupción de una nueva música popular que se extendió rápidamente entre los jóvenes que nacieron después de 1945. No se trata ahora de ver la evolución de esos modelos musicales hasta llegar al tiempo presente, pero sí es necesario aclarar que enseguida construyeron movimientos trasnacionales que conformaron modos de vida no siempre aceptados. Ser beatnik, hippie, teddy boy, rockero, punk, o más recientemente grunge, metalero o hoper, implica un conjunto de valores que quieren ser vividos, y que necesitan un espacio apropiado para desenvolverse. Centrándonos en el Metal Extremo ¿de qué tipo de personas hablamos?

La mayoría de los jóvenes que son aficionados a estas modalidades de música suelen tener una estructura anímica muy fuerte, mente abierta y no sufren grandes desequilibrios psicológicos, sino que su identificación y pertenencia a estas colectividades les proporcionan mucha libertad personal y conciencia de los límites de la vida. ${ }^{14}$ Habitan en el margen pero no son marginados. Como si fuese una comunidad iniciática, la música les introduce en sus propios problemas generacionales y vitales con un calado anímico al que no es capaz de llegar una organización religiosa o un partido político. Los metaleros son personas muy independientes, y al mismo tiempo, prevenidos contra la maquinación

\footnotetext{
14 Hay varios estudios que apuntan en este sentido, entre otros: Viren Swami y colab., «Metalheads: The Influence of Personality and Individual Differences on Preference for Heavy Metal», Psychology of Aesthetics, Creativity, and the Arts 7, no. 4 (2013): 380-381. https://doi.org/10.1037/a0034493. Swami y sus colaboradores concluyen que este género musical atrae a personas de mente abierta porque buscan experiencias novedosas no convencionales y el metal les resulta una música intensa, atractiva y desafiante. Lo que también suele acompañarse de una actitud negativa hacia la autoridad institucional, irreligiosidad y una necesidad muy básica de sentirse singulares, tanto en sentido individual como grupo, que escapa de las corrientes principales, lo que algunos investigadores han señalado como una búsqueda de mejorar su autoestima.
} 
política y el poder del dinero; conscientes de que tras la vida llegará la muerte. La oscuridad, el frío, la tragedia, el fracaso, la impiedad, la nada, son temas usuales en los poemas que se cantan en estos grupos musicales. La falta de futuro suele ser un tema recurrente, e incluso un distintivo visible en el título o contenido de sus canciones.

El Metal Extremo es un fenómeno social del que puede obtenerse información sin mucha dificultad, pero que suele ser descartado desde la investigación pedagógica. No obstante su influencia es universal. Cuando los jóvenes se niegan a consumir comida industrial, se oponen a la destrucción de un bosque o a la crueldad con un animal, o huyen de eventos formales organizados por autoridades, es posible que estemos ante metaleros. ¿Qué piensan de los que no son como ellos? ¿Cómo construyen sus valores reales? ¿Hasta qué punto hay un rechazo a los valores comunes y consensuados de la cultura en que están inmersos? ¿Qué ha quedado en ellos de sus aprendizajes escolares? Las letras de las canciones son una rúbrica de identidad para una banda de rock, lo mismo que para un grupo revolucionario. Una manera de comprender su realidad es leer sus canciones y tratar de entender que mensajes emiten; que testimonio revelan y que significados les podemos atribuir desde una perspectiva educativa. Un análisis superficial podría ofrecer un panorama inquietante, pero las letras satánicas y suicidas, cínicas en ocasiones y en otras tenebrosas, no son el reflejo de una insania de espanto. Christenson y Roberts señalan que los metaleros suelen ignorar el «mensaje» cuando escuchan la música, por lo que, afirma Purcell, no hay una relación directa entre la filosofía individual de los oyentes y el contenido literal de las canciones. Indirectamente, añade, puede existir una relación entre el rechazo de las letras a las normas sociales y lo que viven a diario, apoyándose en el modelo de su «subjetivismo ético». En realidad, las canciones más gore les sirven como metáfora para respaldar opiniones y estilos de vida alternativos. Fuerzan a repensar las normas que se dan por sentado. Posicionándose en un extremo de la ética que los coloca en un absurdo, logran proyectar toda la ética bajo una luz diferente. ${ }^{15}$

\footnotetext{
${ }_{15}$ Natalie J. Purcell, Death Metal Music. The Passion and Politics of a Subculture (Jefferson, NC and London: McFarland \& Company, Inc. Publishers, 2003), 127-130. Para comentar la filosofía de vida y los valores éticos de los metaleros, usa profusamente el trabajo de Peter G. Christenson y Donald F. Roberts, It's not only rock \& roll: popular music in the lives of adolescents (Crestkill, NJ: Hampon Press, 1998).
} 
Las canciones de los grupos de Metal Extremo no siempre pueden escucharse bien en un concierto, porque el uso frecuente de voces guturales lo impide. Los aficionados a esta música deben muchas veces trascender la puesta en escena, y descubrir que le están transmitiendo sus grupos preferidos con lo que cantan. Las letras suelen ser oscuras, escépticas y trágicas. Con frecuencia son deprimentes, pero también cantan la amistad, el amor, y el valor de una gesta. Es una subcultura que tiene mucha relación con los relatos épicos contemporáneos de fantasía, pero los metaleros no viven refugiados en la fantasía, ni en paraísos o infiernos falsos. Sus letras suelen ser crudas e inmisericordes, sin perdón o componendas, sin consuelo. Ocultas tras el growl, las canciones son una llave para entender una revolución de valores, cuyo calado todavía debe descubrirse.

Señala Oksanen que «encontrar una sola interpretación para las letras de rock a menudo es una tarea infructuosa» ${ }^{16}$ porque es necesario prestar atención a sus diferentes conexiones: conviene preguntarse no ya por lo que se narra, sino a que responde. Se suele asociar el rock duro a consumo excesivo de alcohol y drogas, y algunas bandas elogian la bebida pero no siempre se corresponde con vidas arruinadas, ni se adoptan las actitudes que se presentan en las canciones. Se habla a veces de hipermasculinidad en su estética, pero son radicales en la defensa de la igualdad entre hombres y mujeres y es bastante habitual que las bandas tengan chicas como vocalistas e instrumentistas. El rock extremo está ejerciendo mucho influjo sobre la conciencia social de los jóvenes. Es cierto que las canciones suelen presentar temas desolados y sin esperanza, pero tienen un efecto purgativo sobre sus seguidores que alivia su ira y les hace sentirse mejor. ${ }^{17}$

¿De qué hablan las canciones de las bandas de Metal Extremo? Sin duda hay una gran variedad de temas, aunque desde fuera se vean únicamente los textos que producen más rechazo, como el satanismo o el nihilismo, lo que no es insólito entre los grandes movimientos estéticos. ${ }^{18}$ No

\footnotetext{
16 Atte Oksanen, «Drinking to Death: Traditional Masculinity, Alcohol and Shame in Finnish Metal Lyrics», Nordic Studies on Alcohol and Drugs 28, no. 4 (2011) 359.

17 Arnett, 83.

${ }_{18}$ Rubio recuerda la fascinación que Satanás ha producido en algunos de los grandes escritores y compositores de la historia, desde Dante y Telemann hasta Carducci, Paganini, Flaubert o Wagner; antes de acercarnos a los tiempos actuales, en que se para en la idea del Satanás nihilista que «encarna el mal desvinculado de todo lo divino, responsabilidad propia del hombre y de su impulso de
} 
obstante, dice Rubio refiriéndose al death sueco, que incluye el sonido de los grupos finlandeses, que «un disco puede contener un relato sobre asesinos en serie, una crítica blasfema y descarnada al cristianismo o una reflexión abstracta sobre el proceso de morir». Hay himnos satánicos y anticristianos, fantasías terroríficas y postmortem, perversiones asesinas, y también sobre la «guerra y sus apocalípticas consecuencias». Pero también las letras contienen crítica social, temas existenciales y más recientemente las canciones hablan «de la belleza, la reflexión sobre temas estéticos y artísticos o el reflejo de los tropos poéticos tradicionales en la música, como el amor o el erotismo». En la medida que el movimiento avanza «el lenguaje se sofistica de maneras elevadas, hasta el punto de poder considerar su lírica poesía culta». ${ }^{19}$ No es que los temas cantados se dulcifiquen pero ahora se escriben poemas más complejos e insondables. Los músicos no solo quieren ofrecer temas originales en su estilo, sino que las letras que cantan contienen una fuerte emoción y denotan mucha formación literaria. Cuando Swallow the Sun, una banda finlandesa de Melodic Death Metal, editó el triple álbum Songs from the North en 2015, la revista Metal Hammer le dedicó un elogioso artículo que fue comentado por Toni-Matti Karjalainen señalando la frecuencia con que los periodistas se referían a la ubicación de este país en el norte, a su clima severo, al aislamiento de sus bosques y naturaleza, a su mentalidad melancólica, a las pocas palabras de sus gentes; tópicos que determinaban el género narrativo de sus grupos de metal extremo. Este estilo, añade, dio lugar en el siglo XXI a un amplio reconocimiento del metal extremo finlandés en la comunidad metalera global, creando «una suerte de canon» muy presente en los medios de comunicación, la literatura y la escena. ${ }^{20}$

\section{FINLANDIA COMO EJEMPLO MUSICAL DEL METAL EXTREMO}

Finlandia es uno de los países con un movimiento más potente de las corrientes musicales de Metal Extremo. Tiene en conjunto más grupos metaleros que España, 4.002, mientras que Estados Unidos llega hasta

\footnotetext{
autodestrucción». Véase Salva Rubio, «Metal extremo: orgullo y prejuicios (I)», en Jot Down, disponible en https://www.jotdown.es/2016/11/metal-extremo-orgullo-prejuicios-i/ (Consultado el 23/11/2019).

19 Rubio, Metal Extremo, 250-252.

20 Toni-Matti Karjalainen, «Tales from the North and Beyond: Sounds of Origin as Narrative Discourses», en Sounds of Origin in Heavy Metal Music, ed. Toni-Matti Karjalainen (Newcastle upon Tyne: Cambridge Scholar Academics, 2018), 6-8.
} 
los 28.420, ${ }^{21}$ pero Finlandia es el país del mundo que tiene más bandas metaleras per cápita. Su sistema educativo suele presentarse como modélico. Y esa ejemplaridad no solo tiene un importante desarrollo en sus evidencias pedagógicas más conspicuas, en sus hitos de relevancia internacional como los resultados que logra en el informe PISA, sino que también afecta a los jóvenes comunes, sin grandes éxitos académicos, que adquieren una identidad personal a través de la escuela. En Finlandia prosperan todos los subgéneros del metal extremo. No es nuestra intención analizar estas corrientes en su conjunto sino pararnos en algunos casos del Melodic Death Metal, un subgénero que no usa solamente temas gore y voces graves, sino que contienen temas más épicos y alternancia entre voces graves y limpias.

Queremos señalar únicamente la tipología de canciones que hacen tres grupos que en algún momento pudieron definirse como de «melodic death metal», aunque también pueden entenderse como de folk metal u otros estilos, y analizar los perfiles de intereses intelectuales que subyacen en el discurso que construyen: Amorphis, Insomnium, y Wintersun. Estos grupos tienen temas en sus canciones referidas a la naturaleza, a su poder y a sus secretos, con ideas que reivindican el paganismo de sus antepasados, y nos vamos a referir solo a ellas. Hemos examinado 153 canciones de Amorphis entre 1992 y 2018, y 72 de Insomnium entre 1999 y 2019. Finalmente, de Wintersun, hemos registrado 17 canciones entre 2004 y 2017. No hay en sus letras un elogio manso de la tierra, ni del aire libre o la belleza del paisaje, ni su discurso es espesamente identitario. Simplemente emplean esos recursos para aflorar su sensibilidad, consumar una experiencia musical real que refleja un conjunto de ideales que se expresan artísticamente. La naturaleza es aquí usada para expresar los pliegues más recónditos de la mente, los límites de la existencia, la verdad de la muerte y la ausencia de salvación, y preguntarnos para qué vivimos.

Amorphis es el grupo más veterano de los tres. Desde su primera maqueta musical en 1991, Disment of Soul, evolucionaría desde un estilo Death Metal puro hasta ritmos melódicos, ya presentes en su primer álbum, The Karelian Isthmus (1992) en el que usa compases de corte folk y se transforma plenamente en su siguiente álbum Tales from the Thousand

${ }^{21}$ Encyclopaedia Metallum. The Metal Archives, https://www.metal-archives.com/browse/country (Consulta realizada el 20/03/2020). 
Lakes (1994), en el que se introduce una voz limpia, eliminando los blast beats en la bateria, pero al mismo tiempo manteniendo el growl, lo que le permitió formar parte de una corriente que se conoce como «Gothenburg metal», que está en el centro del sonido del Melodic Death Metal. No obstante no se acomodaron a ese estilo, en el tercer álbum Elegy (1996) donde dieron un nuevo giro hacia el metal progresivo, en cuyas canciones «conviven voces guturales con limpias, pianos y teclados, sitar, influencias del rock setentero, complejas estructuras y desarrollos, aires psicodélicos...» usando la recopilación de poemas del Kanteletar. ${ }^{22}$ Insomnium, por su parte, es una banda que ha mantenido un estilo muy inconfundible en toda su trayectoria, utilizando un tono que algunos estudiosos han llamado «doom gótico». Fue ascendiendo en aprecio hasta su más reciente trabajo Heart Like a Grave (1919). Finalmente, Wintersun es un grupo con escasa producción pero muy representativo de esta corriente, que tiene a la naturaleza y el cosmos como eje de sus temas y que usa recursos más sinfónicos.

\section{Amorphis entre la épica nacional y la búsqueda de una espiritualidad pagana}

El poema épico Kalevala forma parte de la identidad finlandesa con tanta profundidad que incluso algunos estudiosos se han preguntado si existiría Finlandia, como estado-nación, si este poema no existiese. ${ }^{23}$ Amorphis usa los relatos del Kalevala en muchas de sus canciones y muestra un estilo que en principio fue death metal para adaptarse más tarde a una corriente doom y más melódica, hasta evolucionar al gothic metal. ${ }^{24}$ Es un grupo que juega mucho con los elementos de la identidad nacional, aunque también hay mucha crítica social en sus canciones y recurre a los elementos de la naturaleza para explicar sus historias. La Encyclopaedia Metallum no lo considera un grupo estrictamente de $\mathrm{Me}$ lodic Death Metal. Su larga trayectoria le llevó a mostrar fuertes huellas de identidad en las tradiciones de su país, sin usar mucha instrumentación folk, más explícita en otros grupos que solo se expresan en finés.

\footnotetext{
22 Rubio, Metal Extremo, 282.

${ }^{23}$ Urpo Vento, «The role of the Kalevala in the Finnish Culture and Politics», in Nordic Journal of African Studies 1, no. 2 (1992): 82. http://www.njas.helsinki.fi/pdf-files/vol1num2/vento.pdf (Consultado el 17/11/2019).

${ }^{24}$ Rubio, Metal Extremo, 45.
} 
El Kalevala fue publicado por Elias Lönnrot en 1835 recogiendo un conjunto de leyendas, poesía popular, folclore y relatos míticos de la cultura finlandesa que acopió viajando por el país y escuchando a los ancianos y siguió con la tarea hasta que en 1849 publicó una edición definitiva. Aunque a los finlandeses suele relacionárseles generalmente entre los pueblos nórdicos, su identidad está determinada por su origen asiático que la historia y el tiempo fue desplazando hacia el occidente. El finés o suomi, no es una lengua indoeuropea, sino urálica que tuvo graves problemas para sobrevivir en el contexto nórdico, ${ }^{25}$ y el Kalevala ayudó mucho a fijarla entre las presiones del sueco por un lado y el ruso por otro. Es un país europeo pero muy particular en su occidentalismo, con una identidad fuerte, construida por la resistencia a no dejarse disolver entre los escandinavos con los que confluyen mucho culturalmente.

Amorphis, introdujo ya en su primer álbum de canciones, The Karelian Isthmus, editado en 1992, uno de los temas territoriales nacionales más importante de Finlandia: la disputa con Rusia por la región de Karelia. Son canciones guerreras, de elogio del valor y la lealtad, y el significado de la muerte, lejos de una concepción cristiana. Salvo la primera canción no hay una referencia directa al tema, incluso usan poemas medievales de la literatura irlandesa, pero todo dentro de un espíritu pagano, donde la naturaleza es dura y grandiosa. Usan su cultura pero sin afán de destacar ningún sentimiento nacionalista. Es el contexto en que viven sin otro acento más que lo que expresan, como en esta estrofa de una de las canciones del disco, Misery Path.

We sail across the sea,

In our thoughts we float over mountains

All this vanity that we could hide

The truth

The truth is to be alive

And to live your life in fear by hate

And create our own gods ${ }^{26}$

\footnotetext{
${ }_{25}$ Pirkko Suihkonen, «The Uralic language», in Fennia 180, no. 1-2 (2002): 167-168. https://fennia. journal.fi/article/view/3774/3565 (Consultado el 17/11/2019)

${ }^{26}$ Navegamos por el mar/En nuestros pensamientos flotamos sobre montañas/Toda esta vanidad que pudimos esconder/La verdad/La verdad es estar vivo/Y vivir tu vida con miedo por odio/Y crear nuestros propios dioses. Todas las letras de las canciones fueron recogidas de la página virtual darklyrics. com y traducidas por el autor.
} 
La identidad de una banda de metal extremo tiene valor a través de los conceptos narrativos y visuales que transmite en su «paisaje cultural» ${ }^{27}$ que en el caso de Amorphis pasó de un ámbito local a convertirse en un fenómeno global que trasciende las fronteras de su país. Su ethos sonoro viene determinado por el uso de una tradición nacional pero que es percibido en un mundo global por jóvenes que siguen unos valores con los que se identifican generacionalmente. El tópico de su identidad finlandesa está fuertemente enraizado en los álbumes que siguieron a The Karelian Isthmus: Tales From A Thousand Lakes (1994), Elegy (1996) y Tuonela (1999), en los que además de utilizar las narraciones del Kalevala, descubre el kantele al mundo, una especie de cítara que simboliza su música tradicional. ${ }^{28}$

Una vez asentados en la fama, ya en el siglo XXI, presentaron un álbum con temas turcos y persas, Far from the Sun (2003) para regresar a los relatos del Kalevala en los años siguientes. En Eclipse (2006) asoma la historia de Kullervo, que ya había inspirado a Sibelius, conforme la interpretación que Paavo Haavikko escribió para una serie de televisión, The Age of Iron en 1982, con música de Aulis Sallinen. ${ }^{29}$ En Silent Waters (2006) recuperó el cuento de la caza del cisne de Tuonela por Lemminkäinen, que también forma parte de la Suite que Sibelius había compuesto en 1895. En 2009 sacaron el álbum Skyforger que cuenta historias en torno a Seppo Ilmarinen, el herrero creador que aparece en el Kalevala. Más recientemente han aparecido otros álbumes: The Beginning of Times (2011), Circle (2013), Under the Red Cloud (2015) y Queen of Time (2018). Lo que resulta más interesante de su trayectoria es que el uso de la poesía tradicional y los relatos mitológicos les dio una visibilidad internacional que es muy apreciada en países como los Estados Unidos y Japón,

\footnotetext{
27 Toni-Matti Karjalainen, Antti Ainamo, Laura Laaksonen, «Occult, a tooth, and the canopy of the sky: conceptualizing visual meaning creation of heavy metal bands», en Design and semantics of form and movement 5: DeSForM 2009, ed. Lin-Lin Chen, et al. (Taipei: s.n., 2009), 23. Disponible en https:// www.academia.edu/30479623/Occult_a_tooth_and_the_canopy_of_the_sky_conceptualizing_visual_ meaning_creation_of_heavy_metal_bands (Consultado el 16/11/2019)

${ }^{28}$ Hannu Tolvanen, «The Quiet Past and the Loud Present: the Kalevala and Heavy Metal», Volume!, 5, no. 2 (2006): 78. El kantele se usaba tradicionalmente para acompañar los poemas recogidos en el Kalevala. Disponible en https://journals.openedition.org/volume/498 (Consultado el 17/11/2019)

${ }_{29}$ Vento, 88. Hasta ese momento, el autor calculaba que existían más de 350 composiciones musicales basadas en el Kalevala.
} 
ya que posiblemente fue el primer grupo de metal extremo en usar esos recursos. ${ }^{30}$

Es un universo legendario, que va mucho con la temática death metal. En los últimos discos evolucionaron hacia un estilo con pinceladas de rock progresivo, sin dejar de inspirarse en los temas del Kalevala cuyas canciones frecuentemente escribe Pekka Kainulainen, un artista que no es músico de la banda. En toda su larga carrera es un grupo que ha sabido crear atmósferas sombrías, llenas de dureza existencial que llaman la atención a sus seguidores. Sus poemas suelen ser inclementes expresando, mediante la metáfora de la epopeya, realidades poco misericordiosas. Y aquí la percepción de la naturaleza es eso: no olvidar que la fatalidad forma parte de lo que somos y que morimos al albur de sus fuerzas. Y también como ante la fatalidad y la dureza de vivir podemos sobrevivir, meditar y enfrentarnos a nuestra suerte. Los ejemplos son frecuentes como en esta canción:

I retired a towering mountain

Laid down in a circle of stones

For three days and for three nights

I listened to the skull of a bear

The sun burnt its sigil into my chest

The rain washed the evil away

Time spun itself around me

The moon cast its silvery shell ${ }^{31}$

El Kalevala inspiró a muchas de las sagas actuales de recreación de ambientes medievales y paganos, como las conocidas obras de Tolkien o Martin, que tanta popularidad adquirió como serie televisiva en su versión de Juego de Tronos. La novela en que se inspira, A Song of Ice and Fire, está muy relacionada con los valores del Metal Extremo, que han apartado a muchos jóvenes de las religiones tradicionales, de la política convencional y del consumo capitalista. Pero además inspiró a muchos otros grupos a crear sus propias historias como es el caso de Kivimetsän Druid, cuyo cantante, Joni Koskinen, escribió The Land of the Crystal

\footnotetext{
${ }^{30}$ Karjalainen, Ainamo, Laaksonen, Occult, a tooth, 28.

31 Me retiré a una gran montaña/Me acosté en un círculo de piedras/Por tres días y por tres noches/ Escuché el cráneo de un oso/El sol labraba su sigilo en mi pecho/La lluvia me limpió el mal/El tiempo giraba a mi alrededor/La luna refulgía su coraza plateada. Under the Red Cloud (2015)
} 
Mountain and Stone Forest, una novela fantástica en la que basan todas sus letras. Turisas utilizó el Kalevala en sus canciones, pero además evocó en dos de sus discos la migración de un grupo de vikingos orientales a Bizancio, a través de la «ruta de los varengos a los griegos».32 En el primero, The Varagian Way (2007) describe el camino que hicieron conforme una crónica del siglo XII; en el segundo, Stand Up and Fight (2011) narra la vida de Constantinopla, incluyendo una carrera en el hipódromo y una visión del Bósforo congelado. ${ }^{33}$ Ensiferum, para terminar con estos ejemplos, es una banda cuyo primer disco lleva el mismo nombre, publicado en 2001. Está dedicado a Väinämöinen, el viejo anciano sabio de voz mágica, que aparecerá en la carátula de este y otros discos de la banda, con la espada y un escudo, en este primero con la bandera de Finlandia. Es quizá el personaje central del Kalevala. ${ }^{34}$

\section{Insomnium: el transcurrir de la vida y la necesidad de reducir la velocidad}

En el caso de Insomnium la naturaleza aparece tratada en varias canciones desde su primer álbum, In the Halls of Awaiting (2002). Son poemas sólidos que responden a la buena formación literaria que tiene su autor, el cantante del grupo Niilo Sevänen, que recoge versos de los poetas fineses más consagrados, como Eino Leino, aunque también usa pasajes de Poe, Bourdillon o Hölderin. Una de sus canciones «In the

32 Era una ruta que partía del Mar Báltico y llegaba por diversos ríos hasta Nóvgorod. De ahí se llegaba al Alto Dniéper, se paraba en la ciudad de Gnëzdovo y se bajaba por el río hasta llegar al Mar Negro. Estos vikingos se convirtieron en la guardia varega de los emperadores de Bizancio, tema de una de las canciones. Sobre esta ruta migratoria vikinga, véase Marta Peña Escudero «La ruta del Este: vikingos y eslavos», en Los vikingos en la historia: I Jornadas de Cultura Vikinga (3-6 de marzo de 2014), Universidad de Granada, ed. Manuel Espinar Moreno y Alberto Robles Delgado (Granada, Nativola, 2014), 149-153. CD-ROM.

${ }_{33}$ Hay un estudio muy detallado sobre estos dos álbumes, que explica las rutas entre los pueblos escandinavos y Bizancio durante la Edad Media y descubre la amplia documentación que Turisas usó para la creación de sus canciones. Véase Antje Bosselmann-Ruickbie, «Heavy Metal Meets Byzantium! Contact between Scandinavia and Byzantium in the Albums "The Varangian Way" (2007) and "Stand Up and Fight" (2011) by the Finnish Band Turisas», en Menschen, Bilder, Sprache, Dinge. Wege der Kommunikation zwischen Byzanz und dem Westen 2: Menschen und Worte, ed. Falko Daim et al. (Mainz, Verlag des Römisch-Germanischen Zentralmuseums, 2018), 391-419.

${ }^{34}$ Kimi Kärki, «Forging Metal: the Kalevala in the Finnish Heavy Metal Performance», en Modern Heavy Metal: Markets, Practices and Cultures. International Academic Research Conference, June 8-12, 2015, Helsinki, Finland, Proceedings, ed. Toni-Matti Karjalainen y Kimi Kärki (Helsinki: Aalto University \& Turku: International Institute for Popular Culture, 2015), 136. http://iipc.utu.fi/MHM/ (Consulta el 16/11/2016). Ensiferum, en latín, el «portador de la espada». 
Groves of Death» del disco Above the Weeping World, está inspirada en un conocido poema de Leino. Destacan en su repertorio varias canciones muy expresivas en relación con la naturaleza, pero es en su penúltimo trabajo Winter's Gate (2016), donde fueron capaces de conjugar la naturaleza con la aventura humana en un único y largo poema, basado en un laureado cuento escrito por Sevänen que narra la historia de un grupo de vikingos que salieron a encontrar una legendaria isla al oeste de Irlanda cuando se acercaba el invierno.

Insomnium es una banda que se fundó en 1997 y en sus primeros tiempos usó el Kalevala en alguna canción como «Song of the Forlorn Son» de su segundo álbum Since the day it all came down, pero se abrió a gustos literarios nuevos y Sevänen pronto buscó otras fuentes de inspiración como el Gilgamesh. Sus canciones son melancólicas y sombrías como si quisiesen ahondar en las leyendas y cantos de gesta más tristes de Finlandia. No obstante dice Ville Friman:

No tratamos sonar depresivos pero eso es algo que sale de forma natural. Y si miras alrededor verás que el mundo está lleno de tristeza, así que a menudo tratamos de forzar menos y concentrarnos en las cosas más felices de la vida. De otra manera la vida sería muy dura. La música es una especie de desahogo para esos pensamientos depresivos y levanta un poco el peso que hay sobre nuestros hombros. ${ }^{35}$

Desde su primera maqueta musical editada en 1999 hasta la actualidad, este grupo ha creado 81 canciones. Ya en 1999, las letras y la música eran de Niilo Sevänen y Ville Friman. En su primer demo, hay una canción muy peculiar por su sentido que encaja en lo que Rubio ${ }^{36}$ llama «el sublime cósmico» del metal: Numen Divinum. Un tipo de poemas que también vamos a encontrar en In the Halls of Awaiting, especialmente en la canción que da título al álbum, aunque quizá lo más inquietante es la atmósfera de sus letras, que aunque referidas en algunos casos a la pérdida del amor, la soledad y alguna glosa al Kalevala, tienen esa apertura a pensamientos sobrecogedores y gélidos, de sentir el universo, de

\footnotetext{
35 Hellpress. «Entrevista a Insomnium. Hablamos con Ville Friman». 28/07/2014. Disponible en http://www.hellpress.com/entrevista-a-insomnium-hablamos-con-ville-friman/ (Consultado el 23/11/2019)

${ }^{36}$ Rubio, Metal extremo: orgullo y prejuicio, s.p.
} 
preguntarnos para qué vivimos. Una atmósfera de inquietud que se afianza en los tres siguientes álbumes: Since the Day it All Came Down (2004), Above the Weeping World (2006) y Across the Dark (2009). La naturaleza, los elementos primordiales del mundo, la luz y el agua, están presentes en los poemas. En uno de ellos Sevänen utiliza uno de los poemas más conocidos de Francis William Bourdillon (1852-1921) que inserta en la canción "Drawn to Black». Con todo, serán otras las canciones con que aborda el sentimiento de la naturaleza, especialmente en "Into the Woods» cuya llamada a ser parte de la foresta, es casi un manifiesto entre deísta y una oración a la naturaleza:

The arch of sky is roof where I call it home

Drizzle of rain, the only music from now on

My bed is made from juniper's boughs

Of mire and moss my pillow. ${ }^{37}$

Lo que parece mostrar la música de Insomnium es una distancia muy grande con las bandas, especialmente con las noruegas de Black Metal y Neofolk, que generaron un movimiento que llegó a incendiar iglesias cristianas, algunos asesinatos, persecución de sacerdotes y pretendían erradicar en el país todo rastro de cristianismo. Un movimiento que también se enraizaba en la extrema derecha, presente en algunas tendencias de este subgénero. ${ }^{38}$ No obstante, el conflicto se desarrolló con mucha menos virulencia en el resto de los países nórdicos. La reivindicación del paganismo y las tradiciones épicas por las bandas finesas no ha conllevado ese fanatismo. En conjunto, los distintos estilos de esta

\footnotetext{
${ }^{37} \mathrm{El}$ arco del cielo es el techo donde lo llamo mi hogar/Orvallo, la única música de ahora en adelante/Mi cama está hecha de ramas de enebro/De lodo y musgo mi almohada.

${ }^{38}$ La adscripción de algunas bandas de Black Metal al nazismo fue más una operación comercial que una opción ideológica. Como señala Rubio, en Metal Extremo, p. 442, fue un movimiento que se define por el rechazo al herd mentality (mentalidad de rebaño) "por el cual el individuo renuncia a sus creencias, objetivos e identidad personal para sumarse a la masa, en forma de creencias religiosas, normas sociales, gustos mainstream o de sumisión a un líder político», lo que sería la negación de esta mentalidad. Algunos miembros del Black Metal querían anular la influencia cristiana sobre Escandinavia y este movimiento tenía hacia 1990 bastante ascendiente en algunas bandas que presumían de satánicas, especialmente en Noruega. Un grupo secreto, Inner Circle, empezó a quemar iglesias, más de cincuenta entre 1992 y 1996, en algunos casos de construcción medieval. La sociedad noruega se alarmó y además Varg Vikernes, miembro de Burzum, se atribuyó en 1993 varios incendios y el asesinato de Euronymus, un guitarrista de Mayhem. Todos estos hechos provocaron una gran conmoción en el país que entró en «pánico moral», tras una campaña de prensa muy dura contra este tipo de música. Ver Kennet Granholm, "'Sons of Northern Darkness": Heathen Influences in Black Metal and Neofolk Music», Numen, 58 (2011): 529-530. https://doi.org/10.1163/156852711X577069
} 
música forman un «sistema cultural complejo» que conforma unas mentalidades que ensayan formas de autenticidad y una búsqueda de espiritualidad que se aleja de las corrientes centrales de las grandes religiones establecidas; e incluso de organizaciones místicas o esotéricas de cierto arraigo. "La atmósfera religiosa de Occidente está cambiando, - dice Granholm - y uno de los resultados de este cambio es que debemos buscar escenarios alternativos de la vida religiosa». ${ }^{39}$

Insomnium no plantea esa espesa conflictividad pero sus canciones son muy contundentes, de tajadura radical con una sociedad complaciente y económicamente desahogada, pero al mismo tiempo su mensaje poético está muy elaborado. Si en otras bandas de metal extremo las letras de las canciones estremecen por su perversidad pero luego esa creencias no desembocan en un tipo de vida destructivo entre sus seguidores, no parece que los miembros de Insomnium vivan cara a un precipicio pero sus preguntas vitales son sobrecogedoras: cuestionan para que vivimos, para que buscamos una meta en la vida cuando el amor queda atrás, y por tanto, debemos caminar despacio, reducir el ritmo, esperarnos unos a otros y caminar hacia adelante, hacia los desconocido. Lo expresan con una especial belleza en su canción más popular:

When you realize that your life is a one-way road

When you realize that there's no point of return

When you understand that you can't go back anymore

When you understand you can only move onwards

And we drift far away in our dreams

Gather further distance while we sleep

Build a wall of glass thick and deep

We hear but choose not to listen

And we drift far away in our dreams

Gather further distance while we sleep

Still the bridge is enflamed with fire

Leave all the love we had behind

Slow down

We need to slow down

So I can catch you

We need to slow down so I can catch you

39 Granholm, 539. 
We need to slow down so you can catch me

Slow down. ${ }^{40}$

El mensaje de Insomnium se hizo mucho más explícito en Winter's Gate, narrando una aventura que llevaba a la perdición, bella y dura, al mismo tiempo que desesperada. La descripción de la tragedia y la muerte helada en el confín del mundo como destino último de quienes salieron de su hogar sin alcanzar heroísmo, tan solo sufrimiento. El último álbum de la banda es muy reciente Heart like a Grave (2019). Su tono es crepuscular, sintiendo el fin de las cosas, o como dice un verso de una de sus canciones, que encabeza este artículo: «Nada está aquí hecho para durar». Un tópico que también utilizan otros grupos del mismo estilo como Dark Tranquility, con menos pesimismo, o grupos indies como Rebel Aces que cantan un tema con un título muy parecido "Nothing Built Last (Springfade)»; o todavía más lejos de ese tipo de música el grupo californiano de synth pop Big Deal, ya desaparecido, tenía una canción con un verso casi idéntico: «Nothing here was built to last». No obstante, el ideario de estos grupos y la intención de las canciones, es muy diferente a las bandas de Metal Extremo.

\section{Wintersun: las estaciones del año y la percepción del paso del tiempo}

La trayectoria de Wintersun es más breve. Tienen solo tres álbumes, pero en todos ellos, la naturaleza y el cosmos es el núcleo que impulsa sus canciones. Su vocalista, Jari Mäenpää, canta gritando, de forma muy peculiar: parece agresivo y que está enfadado. Más que escuchar que dice, sus seguidores se identifican con una forma de expresarse que debe ser interpretada. Por lo que es conveniente parase en leer sus letras: un conjunto de poemas épicos, de raíz nórdica, que en el tercer álbum, The Forest Seasons (2017) presenta una obra sobre las cuatro

\footnotetext{
40 "While We Sleep», Shadows of the Dying Sun (Dortmund: Century Media Records, 2014). Disco $\mathrm{CD}$. Cuando te das cuenta de que tu vida es un camino de ida/Cuando te das cuenta de que no hay punto de retorno/Cuando entiendes que ya no puedes volver/Cuando entiendes que solo puedes avanzar/Y nos alejamos en nuestros sueños/Acumulamos más distancia mientras dormimos/Construye un muro de vidrio grueso y profundo/Oímos pero optamos por no escuchar/Y nos alejamos en nuestros sueños/Acumulamos más distancia mientras dormimos/Todavía el puente está inflamado de fuego/Deja todo el amor que teníamos atrás/Ve más despacio/Necesitamos reducir la velocidad/ Necesitamos reducir la velocidad para que pueda atraparte/Necesitamos reducir la velocidad para que puedas atraparme/Ve más despacio.
} 
estaciones del año, con fuertes componentes sinfónicos, que reúne varios estilos, que ellos mismos y muchos de sus seguidores no dudaron en comparar con Vivaldi. No es cuestión de recurrir a las obras clásicas para entender esta composición musical: nada tienen que ver. Pero sí conviene señalar los hitos de un movimiento que abren caminos sorprendentes en el arte, a nuevas maneras de vivir la realidad, de descubrir idiosincrasias profundas en las mentalidades de las personas que posiblemente se van a consolidar en el futuro. El álbum son cuatro largas canciones, que también se tocan instrumentalmente: Awaken from the Dark Slumber (Primavera); The forest That Weeps (Verano); Eternal Darkness (Otoño), y Loneliness (Invierno). Puede parecer una impertinencia esta comparación con un compositor tan emblemático y universal, pero ciertamente recoge una inquietud que es visible en otros grupos finlandeses: la preocupación por el paso del tiempo, la transformación del paisaje, la dureza de vivir en los extremos habitables, la soledad de la larga noche polar, la llegada del sol sobre los paisajes gélidos, y el canto a la fuerza y poder de otros elementos naturales.

Este estudio no tiene ningún propósito de juzgar la música, sino tratar de encontrar en las letras de las canciones algunos signos que expliquen cómo piensa una parte importante de una generación. Wintersun con solo tres álbumes, y con un impacto considerable en el ambiente metalero, permite realizar un análisis muy completo de las letras de sus canciones. El primer álbum, que tiene el nombre del grupo, Wintersun (2004), canta el fin de la vida y la soledad de la muerte, el mundo helado, la resistencia a la naturaleza salvaje, el paso inexorable del tiempo, la infinitud, el ensueño, la luz entre las sombras...Son ocho canciones que grabó Jari Mäenpää en solitario con el apoyo de un baterista, que hizo que se separase de su anterior banda, Ensiferum. Todas estas canciones, en un trabajo tan personal y coherente ¿qué significan? Sin duda es una pieza, música y poemas, que puede calificarse de obra de arte, o lo que Deleuze y Guattari, llaman obra de arte: un compuesto de sensaciones creado que «se sostiene por sí mismo». ${ }^{41}$ Pero, la realidad de esas sensaciones no implica un ánimo con una identidad fúnebre. Siguiendo el pensamiento deleuziano podríamos utilizar la idea de los «personajes conceptuales». Son poemas que están en la mente del artista, originados

${ }^{41}$ Gilles Deleuze y Felix Guattari, ¿Qué es la filosofía? (Barcelona: Anagrama, 1993), 165. 
por la vivencia de inviernos muy duros, que crean imágenes repulsivas, malas percepciones, malos sentimientos, o movimientos negativos que, conforme los filósofos, inspirarían conceptos originales. ${ }^{42}$

Hay así una distancia grande, no entre las letras y la vida real de los músicos, sino en su irreverencia hacia lo trascendente. Pese al uso de deidades paganas, no hay creencias, sino interrogantes sobre para qué vivimos. El alejamiento de los metaleros nórdicos del cristianismo no es un encuentro insostenible con un paganismo primitivo, sino plantearse cuál es el suelo real de la existencia, que hay detrás de la vida. Su paganismo no es más que un mundo de "personajes conceptuales» que han aflorado usando sus cantos épicos en un nuevo estrato de identidad que está lejos de la idiosincrasia política dominante, aunque se use pródigamente el relato común que se aprendió en la escuela. Mäenpää posee un mundo poblado de imágenes insólitas y dirige su propia relación con el caos hacia dimensiones donde es capaz de crear un universo propio, en el que el más allá está en nuestra dimensión y no implica necesidad de creencias en dioses que nos juzgan y nos manejan a su antojo. Hay muchos ejemplos en sus canciones, pero basta escuchar la primera y muy conocida de este disco, "Beyond The Dark Sun», cuyos versos contienen esta estrofa bien representativa de este discurso descreído:

The dawn will never rise again for my eyes

And I will never sleep again

I've lost my hope time after time

'Cause the light has vanished from the sky. ${ }^{43}$

El segundo álbum Time I, salió en 2012, después de una larga elaboración. Contiene las canciones más estimadas por sus seguidores. Son solo cinco temas y tres canciones (los otros dos temas son instrumentales): la idea de Mäenpää es sacar una segunda parte que, en 2019, todavía no ha salido. En este trabajo se puede ver una mayor cercanía al mundo creado por Martin, más que por la mitología finesa. Son composiciones complejas, de carácter sinfónico, que reivindican más una manera de sentir el mundo que una identidad territorial. De los tres poemas

\footnotetext{
${ }^{42}$ Deleuze y Guattari, ¿Qué es la filosofía?, 65.

${ }_{43} \mathrm{El}$ amanecer nunca más se levantará para mis ojos/Y nunca volveré a dormir/He perdido mi esperanza una y otra vez/Porque la luz se ha desvanecido del cielo.
} 
cantados en el disco, "Sons of Winter and Stars», es la canción más conocida. Es un texto romántico, en su sentido más histórico y fiel, en lo que entendemos como imaginarios extremos:

We fly beyond the birth of the worlds

So old I've become - Thousand years staring into emptiness

But now I realize- That it was just an illusion

All this time I thought it was you that would save the sun

Oh rain comes and washes the hate away

Now I am at the crossroads with questions

Somewhere, someday I will find what I am here for

Who am I.44

Sin perder la profundidad de campo de la anterior, las otras dos canciones tienen un aire muy melancólico. No obstante en «Land Of Snow And Sorrow» vemos algún signo de flaqueza y petición de misericordia cuando suplica «oh carry me away from the cold». En la tercera, «Time», se pregunta por el paso del tiempo, en lo que se muere y se deja atrás, que se va por siempre y para siempre, sin esperar a nadie y en el que nos diluimos: "And I fade away!/When time fades away!/And I'll never feel the same» ${ }^{45}$. Finalmente editaron The Forest Seasons de la que hemos ya comentado sus orígenes e impacto, pero ¿qué indican sus letras? La primavera como despertar de la oscuridad, que deja atrás un mundo viejo; el verano fértil en que somos los gusanos de la tierra y las ramas que alcanzan el cielo: el producto de una podredumbre; el otoño que nos lleva a un más allá del universo infinito, que derriba las capas de la mente: sin principio, ni fin, ni verdad, solo con obscuridad, con la muerte, con la eternidad. Finalmente el invierno: la soledad, sentirse la conciencia única que se va desvaneciendo y ya, cuando nada queda, estar finalmente en casa. Mäenpää presenta las distintas estaciones del año que sobrelleva un bosque finlandés, conforme a su sensibilidad musical, pero marcando hitos del Melodic Death Metal en los poemas que canta. Está refiriéndose a su entorno, como un "punto de orden» en un

\footnotetext{
44 Volamos más allá del nacimiento de los mundos/Tan viejo me he vuelto — Mil años mirando al vacío/Pero ahora me doy cuenta- que era solo una ilusión/Todo este tiempo pensé que eras tú quien salvaría el sol/Oh, la lluvia viene y lava el odio/Ahora estoy en la encrucijada con preguntas/En algún lugar, algún día encontraré para qué estoy aquí/Quién soy.

45 ¡Y me desvanezco! / ¡Cuando el tiempo se desvanece! / Y nunca sentiré lo mismo.
} 
"círculo de control» que marca un territorio, ${ }^{46}$ pero que es visitado por seguidores de otros lugares que van ser influenciados por esas señales (afinidad de comportamientos y adhesión a idearios que se transmiten por mecanismos que suelen desembocar en concentraciones generacionales como los grandes conciertos), que van a marcar modas y formas de pensar que se comparten e intercambian.

\section{ALGUNAS CONCLUSIONES Y UN POSIBLE MODELO PARA FUTURAS INVESTIGACIONES}

Las canciones del metal extremo contienen una temática bastante afín en todas las regiones del planeta. Las letras se desterritorializan y se vuelven a territorializar en otros suelos, donde las ideas y los relatos cantados encuentran puntos de similitud, sea en los países escandinavos o el resto de Europa, Asia, Iberoamérica o los Estados Unidos. Las bandas suelen mezclar las tradiciones culturales con licencias literarias que buscan las raíces de un determinado contorno, en relación con otras manifestaciones artísticas que intentan marcar distancias con la cultura dominante. En España hubo un grupo en Castellón, llamado Runic, que unía las tradiciones gallegas y las escocesas con una urdimbre celta de fondo, expresándose en inglés ¿Es un proceso de aculturación o una moda que sigue el éxito de unas determinadas rodadas para construirse identidades nuevas? Sacó solo dos álbumes y el segundo tenía el oportuno nombre de Liar Flags. ${ }^{47}$ Hay un conjunto de grupos españoles que se consideran "Viking Folk» uniendo algunas señas de identidad locales con el estilo nórdico, pero sin molestarse mucho en examinar fuentes históricas o tradiciones. En otras partes del mundo hay bandas que funden su tradición local al metal extremo: Xipe Totec, es un grupo de Death Metal que canta en náhuatl, usando la mitología azteca y la conquista española como temas; ${ }^{48}$ mientras que Ephemerality (朝生暮死) es una

\footnotetext{
${ }^{46}$ Ronald Bogue, Deleuze's Way. Essays in Transverse Ethics and Aesthetics (Hampshire/Burlington VT: Ashgate Publishing, Ltd., 2007), 27.

47 Destacamos a esta banda porque es un ejemplo muy claro de cómo la globalidad desmantela las identidades por los flujos saturados de información y de la resonancia que un modelo musical puede alcanzar en culturas ajenas al territorio de origen.

48 Xipe Totec es una deidad originaria de la región Yopi, en el suroeste de Oaxaca y una franja de Guerrero, en la llamada Costa Chica y tierra adentro, que fue adoptada por los aztecas. Está documentado por Fray Bernardino de Sahagún y quiere decir «nuestro señor desollado». Véase Gabriel Pareyón, "La música en la fiesta del dios Xipe Totec», III Foro Nacional sobre Música Mexicana,
} 
banda de Beijing, de Melodic Death Metal, que canta en chino, con una vocalista femenina, Tiina, que usa el growl. ${ }^{49}$ En algunos países estas bandas llegan a tener un gran aprecio social, como ocurre con Skálmöld en Islandia, cuyas voces graves se fundieron con la orquesta sinfónica de Islandia en un legendario concierto, que emocionó a toda su ciudadanía. ${ }^{50}$

En el caso de Finlandia, el estudio de las letras de las canciones no lleva automáticamente a establecer una relación entre su contenido y la fortaleza escolar de loa estudiantes, pero sí apunta a que la escuela puede ser responsable de que mantengan una actividad cultural que ayuda a que se entiendan a sí mismos ${ }^{51}$, a sentirse parte de una comunidad a

Zacatecas, 2006. Disponible en https://helda.helsinki.fi//bitstream/handle/10138/25643/XipeTotec. pdf? sequence $=6$ (Consultado el 29/12/2019)

${ }^{49}$ En las bandas de Metal Extremo es frecuente la presencia de vocalistas femeninas muy poderosas en el escenario. Son especialmente conocidas Angela Gossow y Alissa White-Gluz, sucesivas cantantes de Arch Enemy, banda sueca de Melodic Death Metal, que rompieron con los estereotipos de la masculinidad fuerte y agresiva en estos subgéneros musicales. Estos estereotipos han dejado de ser predominantes en los comienzos del siglo XXI, en que la diversidad sexualidad empezó a hacerse más explícita. Para una aproximación a esta cuestión, véase Florian Heesch y Niall Scott (ed,), Heavy Metal, Gender an Sexuality. Interdisciplinary approaches (Oxford/New York: Routledge, 2016). Es especialmente significativo el capítulo de Deena Weinstein «Playing with gender in the key metal» donde después de hacer un examen de cómo se pasa de una masculinidad hegemónica a la diversidad, considera que se está asistiendo a un proceso de postfeminismo donde a veces las mujeres juegan con la masculinidad porque es una música que se ha codificado como masculina. El género, concluye, ya no es un problema tan destacado a como lo ha sido en el siglo XX.

${ }^{50}$ Grupo creado en 2009 que se expresa exclusivamente en islandés. Todas sus letras han sido escritas por Snæbjörn Ragnarsson, un miembro de la banda. Aunque son historias originales del músico, recrean cuentos y leyendas vikingas, y recupera la historia de las Völva: las mujeres chamanes y sacerdotisas que aparecen en el Elder Edda. El concierto con la orquesta sinfónica de Islandia da una dimensión muy exacta sobre la repercusión educativa y de cohesión social que tiene su trabajo. Disponible en https://www.youtube.com/watch?v=5yHsmZy-YS8 (consultado el 29/12/2019).

51 Aunque estos estilos musicales pudieran actualmente considerarse como una parte de la «identidad nacional» finlandesa no están muy presentes en la actividad escolar. El Opetushallitus (Consejo Nacional de Educación) realizó una reforma en 2004 que da mucha libertad a los maestros de música para enseñar varios estilos con gran flexibilidad; en realidad cada docente organiza las enseñanzas musicales conforme lo considera oportuno, sin sujetarse a ningún curriculum establecido. En los conservatorios sufragados por los poderes públicos, la música que se enseña es casi exclusivamente clásica y en algunos casos hay jazz y estilos libres, pero no metal extremo. Véase Marja Heimonen y David G. Hebert, "Nationalism and Music Education: A Finnish Perspective», en Patriotism and Nationalism in Music Education, ed. David G. Hebert y Alexandra Kertz-Welzel. (Oxon/New York: Routlegde, 2012), 167. Más recientemente, entre 2014 y 2017, Finlandia ha reformado sus planes de estudio, tanto en la educación infantil como primaria y secundaria inferior, con un enfoque más multidisciplinar que pone las experiencias de aprendizaje en el centro de la reforma, y en la que los estudiantes de 13 a 15 años fueron ampliamente consultados, especialmente en lo referente a qué era importante en la cultura escolar. Lo que valoraron más fueron factores como la amistad, el respeto, la cordialidad, la confianza, la igualdad y un ambiente de trabajo pacífico. Irmeli Halinen, «The New 
través de la literatura y lengua propia, y al mismo tiempo que se recurre a elementos de circulación trasnacional. Las canciones parten, con frecuencia, de poemas clásicos y populares que se conocen por la escuela, por la herencia que han dejado los grandes poetas fineses, e incluso de las creaciones literarias de los músicos. Es una poética nueva, escasamente académica, pero valiosa y que descubre la fortaleza de su aprendizaje escolar. Las bandas analizadas se expresan en inglés, pero hay otras que lo hacen en finés, y con frecuencia se recurre a la mitología local, entre un rechazo generacional a los valores dominantes en la civilización cristiana europea y la recurrencia a funciones o tópicos universales de la subcultura metalera. Ciertamente la fusión entre el metal extremo y su tradición literaria no fue un chispazo fortuito, sino que antes el rock finlandés dejó fecundarse por las influencias que se movían por el mundo, especialmente anglosajón, y no fue hasta principios de 1990 cuando miraron hacia su propia cultura tradicional, que de repente servía para enriquecer un estilo musical con mucha hibridación cosmopolita.

Tolvanen señala que en 1985 el gobierno, a través del Instituto de Música Folklórica de Helsinki hizo una campaña para que en cada escuela hubiese un kantele, en un tiempo que ya había casi desaparecido y nunca antes se había enseñando a tocarlo en las escuelas y que estas experiencias debieron ser clave en unos niños y adolescentes que pocos años más tarde conformarían esas bandas. La relación que existe ahora en Finlandia entre el Kalevala y los géneros musicales del Metal Extremo es muy sorprendente porque se ha logrado adaptar la cultura tradicional a los intereses de los jóvenes. Los músicos metaleros, huraños y taciturnos, son los que hacen que los escolares se interesen por su propia historia y cultura. ${ }^{52}$ Es un referente difícil de encontrar en otros países cuyas enseñanzas musicales son excesivamente académicas $\mathrm{y}$ formales.

Hay aquí una línea tenue que une los aprendizajes informales con la cultura de la escuela. Es común que estos jóvenes vivan en ambientes

Educational Curriculum in Finland», en Improving the Quality of Childhood in Europe. Volume 7, ed. Michiel Matthes, Lea Pulkkinen, Christopher Clouder, Belinda Heys (Brussels: Alliance for Childhood European Network Foundation, 2018), 80.

52 Tolvanen, 87. 
libertarios que rechazan la cultura escolar pero es en la escuela donde recogieron unas ideas que les sirven para desarrollar sus creaciones musicales, e incluso un imaginario que les diferencia como generación. No es algo privativo de un grupo de jóvenes de un país nórdico. Es un estilo de vida que se sume en un contexto de desterritorialidad. Si por una parte este estilo se fundamenta en una épica autóctona, por otra se diluye en una red que no tiene límites. El metal extremo finlandés se dejó preñar de culturas foráneas pero a su vez se infiltra ahora en la música que está creándose en otros países y continentes. Los metaleros no dejan de ser minorías poco adaptables a los mojones que marcan la superficie cultural dominante de sus países. Es precisamente entre una minoría, que despliega sus creaciones que puntean las distintas situaciones que suceden en la escena, y el territorio, donde Deleuze y Guattari sitúan la música como una operación activa y creativa de desterritorialización del refrain..$^{53}$

Utilizando ese conjunto de ideas que tienen los filósofos franceses podemos pergeñar un esquema explicativo que podría abrir una metodología específica para tratar este fenómeno desde una perspectiva educativa, porque el territorio no determina completamente lo que somos. Los seres humanos tienen autonomía y capacidad de exploración para moverse a otros territorios y modificar su cultura, o adentrarse en lugares remotos y regresar con novedades que transforman el entorno. La identidad personal no está determinada por la narración cultural que se transmite en la escuela. En una sociedad global tan fuertemente intercomunicada, un «refrain» resuena muy lejos y en la medida que los grupos dominantes pueden reconducir los mensajes y controlar su efecto, los temblores no descomponen el paisaje. Es evidente que hay consecuencias graves cuando se quieren realizar cambios drásticos y modificar los escenarios vitales. La quema de iglesias cristianas en Noruega por

\footnotetext{
${ }^{53}$ Bogue, Deleuze's Way, 35. Esta palabra se traduciría al español por «estribillo» pero no refleja así bien lo que quieren decir los autores. La imagen que usan en su discurso es el canto repetitivo de los pájaros, no una estrofa o verso. Puede entenderse también desde el concepto musical de «ritornelo». Conforme Boge el refrain "puede definirse libremente como cualquier patrón rítmico que forme parte de una red de relaciones entre las criaturas y su entorno dentro de un entorno, territorio o dominio social». En el caso de rock y el metal extremo, podría aplicarse a las partes que se repiten, especialmente con la guitarra, conocidas como riffs. El refrain como el riff marcan por una parte el territorio, al mismo tiempo que difunden el sonido más allá del «circulo de control», distribuyendo y fijando los espacios; pero por otra, identifican a una «especie», a un grupo animal o humano que tiene unas características que le hacen partícipe del entorno.
} 
Vikernes y algunos de sus seguidores, su extremismo virulento que reivindicaba el mal, la muerte, el demonio y otras fuerzas ocultas, ${ }^{54}$ produjo un "pánico moral» tan extraordinario en su propia sociedad que incluso estimuló un controvertido «black metal cristiano» que no fue reconocido por los seguidores del movimiento. Lo que no impide que el Black Metal noruego, como otros géneros musicales extremos de la propia Finlandia, constituya actualmente una fuente importante de divisas y goce de protección por las autoridades.

No obstante, más que desatar fenómenos de violencia, lo que busca el metal extremo es la trasgresión de las normas establecidas, cuestionar el statu quo de la sociedad en la que viven. La música, las letras de las canciones, la forma de presentarse en escena, los gustos y opiniones manifestadas, y desde luego la forma de vestirse y labrar el propio cuerpo quieren sacudir las mentalidades instaladas en una vida confortable y con creencias firmes. No es extraño que puedan producir "pánico moral»,55 no tanto porque carezcan de fuertes convicciones éticas, sino porque cuestionan la moral dominante en el territorio y proponen una forma de vida que produce desorden. La trasgresión es quizá la palabra clave para entender esta subcultura, porque el principal elemento de su capital cultural es un escenario de trasgresión pacífica y libre, aunque, como señala Kahn-Harris, en el borde de lo aceptable. ${ }^{56}$

Lo más interesante desde un análisis histórico-pedagógico es que estas canciones que hemos revisado están impregnadas de tradiciones y educación finlandesa que se posee por el sedimento de aprendizaje que deja la escuela, pero que al mismo tiempo hay una percepción de pertenencia a una colectividad que encuentra iguales en otros países y continentes. Desconocemos como esto irrumpe en unos espacios que ordenan los valores culturales que se consideran centrales en la formación de los jóvenes. Aquello que aprendemos, con amor u odio en la escuela, adquiere

\footnotetext{
${ }^{54}$ Deleuze y Guattari han estudiado este fenómeno. Véase en Bogue, «Violence in Three Shades of Metal Death, Doom and Black», en Deleuze's Way, 35-52.

55 Titus Hjelm, Keith Kahn-Harris, Mark LeVine, «Heavy metal as controversy and counterculture», Popular Music History 6 no.1/2 (2011): 7-8.

${ }_{56}$ Keith Kahn-Harris, Extreme Metal: Music and Culture on the Edge (New York: Berg Publishers, 2007), 30 .
} 
un poso que no es sencillo controlar posteriormente ¿Qué queda de la cultura escolar en las personas jóvenes cuando empiezan a sentirse independientes y con control de su vida? Lo que resulta evidente en estas bandas es que poseen un bagaje de cultura escolar amplio que les permite escribir, crear y reflexionar sobre sus intereses. Arrastran tradiciones que se aprenden en el ámbito escolar, que transmite unas ideas básicas de música, historia y literatura, y desde luego actividad al aire libre en plena naturaleza, que es consustancial a un modo de vida que marca con un sigilo invisible su personalidad, su concepción del mundo. No obstante todo ese material que se recoge de la escuela lo trasladan a otro espacio, mediante un tintineo que retumba lejos y es reconocido por copartícipes en el refrain que se solidarizan levantando la mano para hacer el «maloik» ${ }^{57}$. El rechazo que sostiene la cultura metalera a los patrones mentales y modo de vida del mundo occidental en nuestro tiempo, no es un fenómeno sin consecuencias. Está produciendo una trasmutación de valores en un segmento importante de la población que genera modos educativos que deben ser estudiados.

\section{Nota sobre el autor}

Eugenio Otero Urtaza es catedrático de Teoría e Instituciones Contemporáneas de la Educación. Desde 1979 es profesor de la Universidad de Santiago de Compostela en el Campus de Lugo. Fue Director de su antigua Escuela de Formación del Profesorado entre 1994 y 2003. Desde 2011 impulsó y coordina el máster en Dirección de Actividades Educativas en la Naturaleza, de perfil multidisciplinar y único en España. Destacado especialista en el estudio de la Institución Libre de Enseñanza, tema sobre el que ha publicado varios libros y más de setenta artículos y capítulos de libros, en los que ha abordado diferentes aspectos del florecimiento cultural y educativo desencadenado por Francisco Giner a partir de 1876. Se ha ocupado especialmente del estudio del Patronato

\footnotetext{
57 Sam Dunn, Jessica Joy Wise y Scot McFadyen. Metal: A Headbanger's Journey [Film documental]. Toronto, Canada: Banger Productions Inc., 2005), 38:00. El gesto del «maloik» o «mano cornuta» que alzan los metaleros fue difundido por el segundo cantante de Black Sabbath, Ronnie James Dio. Es una señal de saludo por el que se desea no padecer ningún mal. «Maloik» es una alteración de la palabra italiana «maloccchio», mal de ojo.
} 
de Misiones Pedagógicas, la trayectoria intelectual de Manuel B. Cossío, algunos de sus epistolarios inéditos, sus viajes e ideas pedagógicas, así como su dimensión internacional y relación con destacados educadores europeos.

\section{REFERENCIAS}

Arnett, Jeffrey . Adolescents and Heavy Metal Music». Youth\&Society 23 no.1 (1991): 76-98. https://doi.org/10.1177/0044118X91023001004

Bogue, Ronald. Deleuze's Way. Essays in Transverse Ethics and Aesthetics. Hampshire/Burlington VT: Ashgate Publishing, Ltd., 2007.

Bosselmann-Ruickbie, Antje. «Heavy Metal Meets Byzantium! Contact between

Scandinavia and Byzantium in the Albums "The Varangian Way" (2007) and "Stand Up and Fight" (2011) by the Finnish Band Turisas». En Menschen, Bilder, Sprache, Dinge. Wege der Kommunikation zwischen Byzanz und dem Westen 2: Menschen und Worte, editado por Falko Daim et al., 391-419. Mainz: Verlag des Römisch-Germanischen Zentralmuseums, 2018.

Coombs, Philip H. y Manzoor Ahmed. La lucha contra la pobreza rural. El aporte de la educación no formal. Madrid: Tecnos, 1975.

Deleuze, Gilles y Felix Guattari. ¿Qué es la filosofía?. Barcelona: Anagrama, 1993.

Dimock, Michael. «Defining generations: Where Millennials end and Generation Z begins». Pew Research Center, January 17 (2019). https://www.pewresearch.org/fact-tank/2019/01/17/where-millennials-end-and-generation-z-begins/

Dunn, Sam, Jessica Wise y Scot McFadyen. Metal: A Headbanger's Journey [Film documental]. Toronto, Canada: Banger Productions Inc., 2005.

Fried, Carrie B. «Stereotypes of Music Fans: Are Rap and Heavy Metal Fans a Danger to Themselves or Others?». Journal of Media Psychology 8, no. 3 (2003): 1-27.

Granholm, Kennet. "Sons of Northern Darkness": Heathen Influences in Black Metal and Neofolk Music». Numen 58 (2011): 514-544. https://doi.or$\mathrm{g} / 10.1163 / 156852711$ X577069.

Halinen, Irmeli. «The New Educational Curriculum in Finland». En Improving the Quality of Childhood in Europe. Volume 7, editado por Michiel Matthes, Lea Pulkkinen, Christopher Clouder, Belinda Heys, 75-89. Brussels: Alliance for Childhood European Network Foundation, 2018. http://www.allianceforchildhood.eu/files/Improving_the_quality_of_Childhood_Vol_7/QOC\%20 V7\%20CH06\%20DEF\%20WEB.pdf

Heimonen, Marja y David G. Hebert. "Nationalism and Music Education: A Finnish Perspective». En Patriotism and Nationalism in Music Education, 
editado por David G. Hebert y Alexandra Kertz-Welzel, 157-174. Oxon/New York: Routlegde, 2012.

Karjalainen, Toni-Matti. «Tales from the North and Beyond: Sounds of Origin as Narrative Discourses». En Sounds of Origin in Heavy Metal Music, editado por Toni-Matti Karjalainen, 1-40. Newcastle upon Tyne: Cambridge Scholar Academics, 2018.

Karjalainen, Toni-Matti, Antti Ainamo y Laura Laaksonen. «Occult, a tooth, and the canopy of the sky: conceptualizing visual meaning creation of heavy metal bands". En Design and semantics of form and movement 5: DeSForM 2009, October 26-27, editado por Chen, Lin-Lin. et al., 20-32 Taipei: s.n., 2009. https://www.academia.edu/30479623/Occult_a_tooth_and_the_canopy_of_the_sky_conceptualizing_visual_meaning_creation_of_heavy_metal_bands

Kärki, Kimi. «Forging Metal: the Kalevala in the Finnish Heavy Metal Performance». En Modern Heavy Metal: Markets, Practices and Cultures. International Academic Research Conference, June 8-12, 2015, Helsinki, Finland, Proceedings, editado por Toni-Matti Karjalainen y Kimi Kärki, 131-137. Helsinki: Aalto University \& Turku: International Institute for Popular Culture, 2015. http://iipc.utu.fi/MHM/

Kato, Keizo y Akinori Ito. «Acoustic Features and Auditory Impressions of Death Growl and Screaming Voice». En Proceedings of the 2013 Ninth International Conference on Intelligent Information Hiding and Multimedia Signal Processing, editado por Kebin Jia et al. Beijing, China: IEEE, 2013. https:// doi.org/10.1109/IIH-MSP.2013.120

Martín-Barbero, Jesús. «Jóvenes: des-orden cultural y palimpsestos de identidad». En Viviendo a toda. Jóvenes, territorios culturales y nuevas sensibilidades, editado por Humberto J, Cubides et al., 22-37. Santa Fe de Bogotá, Colombia: Siglo de Hombre Editores, 1998.

McLaren, Peter. «Revolutionary Pedagogy in Post-revolutionary Times: Rethinking the Political Economy of Critical Education». Educational Theory 48, no.4, (1998): 431-462.

Oksanen, Atte. «Drinking to Death: Traditional Masculinity, Alcohol and Shame in Finnish Metal Lyrics». Nordic Studies on Alcohol and Drugs 28, no. 4 (2011) 357-372.

Pareyón, Gabriel. «La música en la fiesta del dios Xipe Totec». En III Foro Nacional sobre Música Mexicana, Zacatecas, 2006. Inédito. https://helda.helsinki.fi//bitstream/handle/10138/25643/XipeTotec.pdf?sequence $=6$

Peña Escudero, Marta. «La ruta del Este: vikingos y eslavos». En Los vikingos en la historia: I Jornadas de Cultura Vikinga, 2, 4, 5 y 6 de marzo de 2014, Universidad de Granada, editado por Manuel Espinar Moreno y Alberto Robles Delgado, 149-153. Granada: Nativola, 2014. CD-ROM. 
Purcell, Natalie J. Death Metal Music. The Passion and Politics of a Subculture. Jefferson, NC and London: McFarland \& Company, Inc. Publishers, 2003.

Rubio, Salva. Metal Extremo. 30 años de obscuridad (1981-2011). Lleida: Editorial Milenio, 2011.

Suihkonen, Pirkko. «The Uralic language». Fennia 180, no. 1-2 (2002): 165-176.

Swami, Viren y colab., «Metalheads: The Influence of Personality and Individual Differences on Preference for Heavy Metal». Psychology of Aesthetics, Creativity, and the Arts 7 no. 4 (2013): 377-383. https://doi.org/10.1037/ a0034493

Tolvanen, Hannu. «The Quiet Past and the Loud Present: the Kalevala and Heavy Metal». Volume! 5, no. 2 (2006): 75-89. https://journals.openedition.org/ volume/498

Vento, Urpo. "The role of the Kalevala in the Finnish Culture and Politics». Nordic Journal of African Studies 1, no. 2 (1992): 82-93.

Weinstein, Deena. Heavy Metal. A Cultural Sociology. New York: Lexington Books An Imprint of MacMillan Inc., 1991.

Weinstein, Deena. «Just So Stories: How Heavy Metal Got Its Name - A Cautionary Tale». Rock Music Studies 1, no. 1 (2014): 36-51. https://doi.org/10.108 0/19401159.2013.846655

Weinstein, Deena. «Playing with gender in the key metal». En Heavy Metal, Gender and Sexuality. Interdisciplinary approaches, editado por Florian Heesch y Niall Scott, 11-25. Oxon/New York: Routledge, 2016.

Wilson, Ross. «Folk Metal Case Study». En Inmortalis Productions. https:// rosswilsondrmetal.wordpress.com/ 